\title{
A Longitudinal Study of Interactions Between Health Professionals and People With Newly Diagnosed Diabetes
}

\author{
Anthony Dowell, $M B C b B^{1}$ \\ Maria Stubbe, $P b D^{1}$ \\ Lindsay Macdonald, $M A^{1}$ \\ Rachel Tester, BSc, GradDipSci ${ }^{1}$ \\ Lesley Gray, MPH ${ }^{1}$ \\ Sue Vernall, $R N^{1}$ \\ Tim Kenealy, $M B C b B, P b D^{2}$ \\ Nicolette Sheridan, $P b D^{2}$ \\ Barbara Docherty, PGDipHSc, RN ${ }^{2}$ \\ Devi-Ann Hall, RN ${ }^{2}$ \\ Deborab Raphael, BA, MA ${ }^{2}$ \\ Kevin Dew, $P b D^{3}$ \\ 'Department of Primary Health Care and \\ General Practice, University of Otago, \\ Wellington, New Zealand \\ ${ }^{2}$ Faculty of Medical and Health Sciences, \\ The University of Auckland, Auckland, \\ New Zealand \\ ${ }^{3}$ School of Social and Cultural Studies, \\ Victoria University of Wellington, \\ Wellington, New Zealand
}

Conflicts of interest: authors report none.

\section{CORRESPONDING AUTHOR}

Anthony Dowell, MBChB

Department of Primary Health Care and General Practice

University of Otago, Wellington

PO Box 7343

Wellington 6242, New Zealand

tony.dowell@otago.ac.nz

\begin{abstract}
PURPOSE We undertook a study to observe in detail the primary care interactions and communications of patients with newly diagnosed diabetes over time. In addition, we sought to identify key points in the process where miscommunication might occur.
\end{abstract}

METHODS All health interactions of 32 patients with newly diagnosed type 2 diabetes were recorded and tracked as they moved through the New Zealand health care system for a period of approximately 6 months. Data included video recordings of patient interactions with the health professionals involved in their care (eg, general practitioners, nurses, dietitians). We analyzed data with ethnography and interaction analysis.

RESULTS Challenges to effective communication in diabetes care were identified. Although clinicians showed high levels of technical knowledge and general communication skill, initial consultations were often driven by biomedical explanations out of context from patient experience. There was a perception of time pressure, but considerable time was spent with patients by health professionals repeating information that may not be relevant to patient need. Health professionals had little knowledge of what disciplines other than their own do and how their contributions to patient care may differ.

CONCLUSIONS Despite current high skill levels of primary care professionals, opportunities exist to increase the effectiveness of communication and consultation in diabetes care. The various health professionals involved in patient care should agree on the length and focus of each consultation.

Ann Fam Med 2018;16:37-44. https://doi.org/10.1370/afm.2144.

\section{INTRODUCTION}

$\square$ iabetes is a major global cause of morbidity, ${ }_{1}^{1,2}$ and prevalence of this diagnosis is predicted to increase substantially in the next 20 years. ${ }^{3}$ Although the impact of diabetes is largely a function of both social determinants of health and genetic predisposition, ${ }^{3,4}$ an important determinant of outcome in primary care settings is the effectiveness of the consultation between patients and health care professionals. ${ }^{5,6}$

Diabetes management is now focused on primary care settings ${ }^{7}$ and multidisciplinary team care. ${ }^{8}$ Multidisciplinary care presents challenges related to the consultation styles ${ }^{9}$ of different health professionals, ${ }^{10}$ and the different relationships patients develop by engaging in a linked sequence of consultations with professionals from both primary and secondary care.

The quality of communication between health professionals and patients makes a substantial difference in health outcomes. ${ }^{5,11-13}$ Despite increasing awareness of patient-centered approaches, research suggests effective communication can be difficult in routine practice. ${ }^{14,15}$

In diabetes care, patients report challenges when it comes to communication with health professionals including perceptions of a rushed, impersonal style, ${ }^{16-18}$ an exclusion of their participation, ${ }^{19}$ and difficulties with the biomedical model used. ${ }^{20,21}$ Clinicians are aware of some of these communication issues ${ }^{22}$ and can change their communication patterns over 
time, building an effective nurse-patient ${ }^{6}$ or physicianpatient relationship in early consultations, progressing to discussing treatment matters, and then addressing psychosocial issues. ${ }^{23,24}$

Audio-taping and videotaping of consultations $\mathrm{s}^{25,26}$ are being increasingly used to explore the management of diabetes ${ }^{27-31}$ and antecedents such as overweight and obesity. ${ }^{32}$ Further research has been called for ${ }^{23}$ including exploration of physicians and patients "talking past one another ${ }^{\prime \prime 3}$ and interactions between nonphysician health care professionals and patients.

There is little existing research directly observing the patient journey and interactions with different health professionals from the onset of diabetes. We undertook video observation of a cohort of patients with newly diagnosed diabetes to gain an in-depth picture of communication and miscommunication processes within a primary health care team over time.

\section{METHODS}

We observed all interactions between 32 patients with newly diagnosed diabetes and their health professionals for 6 months. This study was approved by the national multicenter Health and Disability Ethics Committee (reference LRS/08/09/041).

\section{Practices and Setting}

Patients were recruited from general practices in the Auckland and Wellington regions of New Zealand. Ten practices were selected through academic and clinical contacts on the basis of their demographically diverse population bases and willingness to participate in intensive qualitative research.

\section{Patient Recruitment}

Patients were purposively recruited to obtain variation within the sample on age and ethnicity, and similar numbers of women and men. The sample had typical presentations of diabetes for a community population and excluded patients having emergency presentations. Participating physicians recruited eligible patients during the general practitioner consultation wherein the diagnosis of diabetes was first discussed after a blood test.

Consenting patients were asked to participate in a project observing "general issues of communication in health care"; diabetes was not specifically mentioned. Consultation tracking was patient driven: patients informed the researchers of the date, time, and location of subsequent health professional contacts.

\section{Data Collection and Analysis}

We video-recorded the initial postdiagnosis consultation and all subsequent interactions between the patient and health practitioners for 6 months. Cameras were placed in an unobtrusive location in the consultation room. The videotapes were subsequently transcribed.

The unit of analysis was the collective set of all episodes of care for an individual patient. We reviewed data longitudinally for each patient and made comparisons across patients. Collated data were reviewed for themes by a core multidisciplinary team (A.D., M.S., L.M., T.K., N.S., K.D.), individual perspectives were moderated by the group, thereby ensuring the conclusions drawn were balanced and grounded in the study's data.

Analysis entailed both linguistic and sequential analysis of individual interactions and texts, and broader ethnographic descriptions of diabetes care and its communication patterns and systems.

We assessed the key decision points in each patient's care for both effective communication and its relationship to appropriate clinical outcome, to understand how satisfactory or unsatisfactory outcomes and decision points were reached.

Interaction analysis was used to examine the interactions at various key moments in the diabetic care pathway $^{34}$ and the analysis focused on potential sites of miscommunication, particularly evaluating the impact of differing patient ethnicity, age, and sex. ${ }^{35}$ This linguistic and ethnographic analysis was integrated with analysis of the interactions from a clinical perspective, ${ }^{36,37}$ enabling the pragmatic approach required to answer complex health systems research questions. ${ }^{38}$

\section{RESULTS}

There was wide variation in the consultation pattern for the 32 patients over the 6 -month period. The number of consultations per patient ranged from 1 to 12 , and the overall duration of individual patient visits to health professionals was between 27 minutes and 7 hours, 12 minutes. Physician consultations averaged 22 minutes (range $=6$ to 56 minutes), nurse consultations averaged 41 minutes (range $=8$ to 95 minutes), and dietitian consultations averaged 24 minutes (range $=17$ to 52 minutes). Examples of 2 contrasting patient contact profiles are shown in Figure 1.

Our exploration of the data provided a set of overarching themes that illustrate the main features of care experienced by patients in the 6 months after clinical diagnosis of diabetes. These themes, together with some illustrative quotes, are shown below. Specific participants are denoted by an abbreviation-patient $(\mathrm{PT})$, general practitioner $(\mathrm{GP})$, nurse $(\mathrm{NS})$, and other health professional (HP)—and number. 


\section{Figure 1. Examples of time spent with patients over the 6-month period.}

Example 1: PT02 Timeline

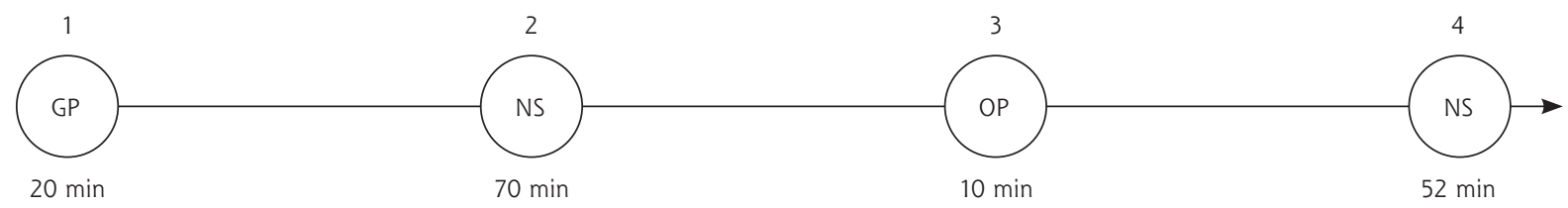

Total recorded consultation time: 2 hr 32 min

Example 2: PT04 Timeline

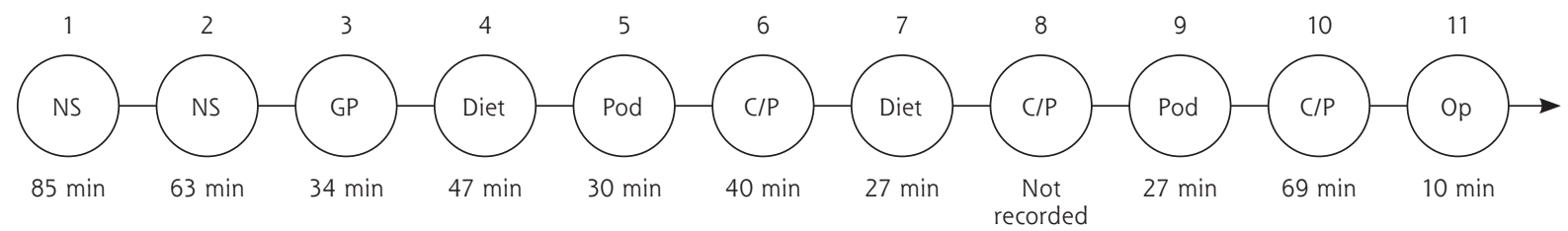

Total recorded consultation time: $7 \mathrm{hr} 12 \mathrm{~min}$

C/P = care plus (nurse plus general practitioner); Diet = dietitian; GP = general practitioner; NS = nurse; OP = optometrist; Pod = podiatrist; PT = patient.

Notes: In example 1, the patient had 4 contacts in 6 months (1 with the general practitioner, 2 with the practice nurse, 1 with an optometrist), and consultation times ranged from 10 to 70 minutes. In example 2 , the patient had 11 contacts with a variety of professionals in 6 months, and consultation times ranged from 10 to 85 minutes. Spacing of encounters does not reflect actual intervals between them.

\section{System of Diabetes Care}

Throughout the sequence of consultations, there was evidence of systematic coordination of care, with all patients managed through nationally developed protocols and guidelines. In every consultation, health professionals focused on biomedical aspects of care (discussion of blood tests, dietary advice, or podiatry advice) and gave attention to the patient's psychosocial context. They showed high levels of generic communication skill and expertise in establishing rapport, dealing with multiple patient and professional agendas, and providing information.

\section{Initial Consultations}

We identified pressure in early consultations to deliver a checklist of facts and perform laboratory tests. A checklist forms an integral part of the national management protocol for diabetes ${ }^{39}$ and was used, to varying degrees, in all practices.

In the majority of consultations, initial conversation sequences were driven by health professionals using information packaged to explain diabetes from a biomedical perspective as exemplified here (first general practitioner consultation, GP01 and PT04):

GP: We regard for lots of purposes this resistance to insulin as a core problem, if you like, which causes a whole lot of other things ... Your body resisting insulin actually commonly makes you gain weight, commonly makes your sugar go up as in diabetes.
This general pattern was occasionally contrasted by a more patient-centered pattern allowing incorporation of the patient's knowledge into subsequent information provision (first general practitioner consultation, GP17 and PT01):

GP: I'd like firstly to know, briefly if you like, what you know or understand about diabetes currently, and I'd also like you to tell me how you feel about that or how you react to that.

\section{Preexisting Knowledge of Diabetes}

Health professionals appeared to approach most initial (and many subsequent) consultations with the assumption that diabetes was a new condition about which the patient had little knowledge. Patients often had preexisting knowledge of diabetes, however, either from their own expectation of getting the condition (eg, because all family members had it) or because they had already ascribed symptoms to the development of the condition (first consultation with general practitioner, GP16 and PT01):

PT: I already knew something about diabetes because of some of the symptoms, and I made a lot of changes.

\section{GP: Oh yes.}

PT: I don't fry as much as I used to. We like our food and we have to have less fat, I do know that you know. I suppose to eat healthy but can't always do that. 
Although health professionals noted patients' prior knowledge, they seldom used this knowledge as a subsequent focus to decide what the patient needed.

\section{Duplication of Information}

We often observed unplanned duplication of information as patients consulted different health professionals over time. There was rarely any checking of previous information imparted.

In the example below, the same patient (PT01) is offered introductory information about diabetes on sequential occasions from both the practice nurse and the general practitioner. At the first nurse consultation, the nurse (NS12) offers information:

NS: I'll give you a booklet, which will give you an idea ...

At the second nurse consultation, the nurse repeats the offer, and the patient reminds her of the previous exchange:

NS: Do you want some pamphlets that I have printed out?

PT: Well, I've gone through all the other information you gave me last time I was here.

In the consultation with the general practitioner (GP01), the patient is again offered the same information, albeit in a different format:

GP: ... there's several diagrams that I like to show people ...

$\mathrm{PT}: \ldots \mathrm{mmm} \ldots$

GP: ... just by way of basic explanation.

\section{Coordination of Care}

Health professionals nearly always gave patients information about a planned referral pathway from the initial general practitioner and practice nurse consultations. This information usually took the form of brief descriptions of other professionals' roles, as exemplified in this interaction (first general practitioner consultation, GP01 and PT04):

GP: ...Then we run here a diabetic clinic or a clinic for people who've got problems with the sugar and the fats and so on ...

PT: Yep.

GP: ... and that's run by one of our nurses who's done a lot of kind of training in this area...

In many consultations, however, health professionals appeared to assume that patients would receive little input from other health professionals, and commonly provided information that took a single-discipline approach to diabetes as a problem (podiatrist consultation, HP07 and PT01):

HP: Let's have a look here 'cause I think you also see the diabetes nurse educator. I'll just explain a little bit about our [podiatry] service. We're funded by our Health Board to reduce amputation rates and prevent hospitalization due to diabetes.

\section{Social Context}

There were many instances in which health professionals acknowledged the patient's social context and recognized the difficulties posed by low income or family and life complexity, as was evident in this exchange (general practitioner consultation, GP18 and PT01):

PT: I just said all they want me to do is to go back to work.

GP: But you've still got your sickness benefit current, haven't you?

PT: No, they stopped that when he [my husband] got paid.

GP: Do we need to do anything about that?

Another prevalent discourse pattern, however, was for a health professional to give advice without much consideration of the patient's social context. In the conversation below, the physician remains focused on a need to convey advice about a set regimen of exercise rather than listening to the patient's narrative about her social challenges (general practitioner consultation, GP27 and PT01):

PT: Um, me, I've got an older sister to look after that's had a stroke.

GP: So you take her for a walk twice a week?

PT: So (inhales) you know ... I work with preschoolers I'm walking around all day.

GP: It's not good enough.

PT: It's not good enough? Ob cripes.

GP: You need to be working up a sweat.

PT: Oh oh.

GP: Every day.

PT: Oh crikeys.

\section{Structure of the Consultation}

Diabetes care was carried out in a variety of different consultation contexts, ranging from general practitioner consultations of 15 minutes in duration to structured care appointments in primary care diabetes clinics last- 
ing for more than an hour. The format of the latter provided opportunities to cover a range of important topics such as foot care and psychological issues, but the need to cover all the points on the nationally derived checklist meant that the interactional flow of natural conversation was frequently interrupted.

In the example below, a nurse is conducting an interview as part of a structured module of funded care. The consultation has focused on psychological and emotional factors associated with diabetes when the nurse realizes that there are other issues to be covered in that session (nurse consultation, NS13 and PT03):

PT: It puts it into perspective if you talk about it, yeah.

NS: So you talk to friends?

PT: I talk to anybody who's silly enough to listen.

NS: Yeah, I think women are like that though.

PT: I think that's how ... we manage things and-

NS: Teeth is the other area.

The dialog shows a very abrupt change in topic focus, with a loss of emotional continuity apparent in evaluation of both the audio and the video.

\section{Evolution of Self-Management}

Each sequential consultation gave an opportunity to observe changes in the way in which patients viewed and described their diabetes over time and could become more knowledgeable about the principles of self-management. By the end of the 6-month study period, many patients had become fluent in diabetes terminology when speaking about their condition and the facilitators of and barriers to self-control.

In the example below, the patient had been seen on 4 occasions by 3 different health professionals over the 6 -month period. In the first consultation, where diagnosis was initially discussed, the general practitioner (GP03) assumed the patient (PT03) had little expertise:

GP: Right, in keeping with diabetes, and that's really what we thought we'd get you in to talk about today.

By the fourth consultation, with a practice nurse (NS13) after 4 months, the patient had become expert with many aspects of diabetes such as regular blood testing and retinal screening:

PT: I don't know whether or not my blood test showed up any worse than it was before or not.

NS: You've just had some tests as well, we'll go through those

PT: And the eye test definitely was fine so...
In other cases, health professionals maintained a very didactic consultation style. In the following exchange, after a 6 -month period of follow-up and review, there was still very little inquiry regarding how the patient was self-managing diabetes (general practitioner consultation, GP27 and PT01):

GP: But don't have something sweet every day with every meal ...

PT: No.

GP: ... If there's something you really like, ...

PT: Yep.

GP: ... then have it as a special treat and really enjoy it.

PT: Yeah.

GP: But every day, do food which doesn't have a lot of sugar.

\section{DISCUSSION}

This is the first longitudinal study to directly observe the health interactions of a cohort of patients with newly diagnosed diabetes in routine primary care. These data were derived from New Zealand primary care, however, because of the structural similarity of primary care and diabetes management across regions and countries, the identified issues are also of high relevance and importance internationally.

The strength of our study lies in the comprehensive and longitudinal nature of the data set, and the multiple methods used for analysis. The use of 2 different geographic locations broadens generalizability of the findings. The practitioners recruited into the study were unaware of the full range of aims for consultation recording, thereby reducing the potential for artificial bias in the conversations.

A number of potential study limitations also exist. They include lack of examination of body language and behavior in the analysis, and the possible intrusiveness of the regular videotaping process for patients. In addition, general practitioners were asked to avoid initial telephone consultations, which might be part of their normal care for patients with diabetes.

Our results highlight the important role that communication plays in diabetes management, and the overall commitment of primary care teams to delivering patient care. ${ }^{40}$ They also identify a number of important themes where the structure and style of current practice may stand in the way of optimal outcomes, as detailed below.

\section{Communication and Patient-Centeredness}

The overall findings suggest that despite high levels of generic communication expertise among health profes- 
sionals, many patients found the style and content of health promotion and lifestyle advice divorced from their reality or experience, exemplified by the encounter between GP27 and PT 01 above. These findings affirm other work identifying a relative absence of a patient-centered perspective. ${ }^{6,20}$ In some consultations, the focus was on simply providing information, ${ }^{40}$ with relatively little emphasis on the structured negotiation techniques noted previously to effect lifestyle change. ${ }^{29}$ Furthermore, the requirement to use a structured checklist approach can lead to loss of more engaged communication technique, as was seen in the interaction of NS13 and PT03. We concur with previous patient interview ${ }^{16}$ and individual nurse observation $^{41}$ studies that consultations were most effective when practitioners actively remained within a patient frame of reference, and encouraged narrative, as seen in the exchange between GP17 and PT01 showing patient-centric questioning.

Collectively, these findings suggest that there is benefit in reemphasizing the principles of good patient-centered communication skills and placing them within a more biopsychosocial framework.

\section{Initial Diagnosis and a Biomedical Model}

Our cohort of patients had extensive preexisting awareness of the likelihood of diabetes, and many expressed little surprise at the diagnosis. In virtually all cases, the initial consultation took the form of a biomedical discourse, meaning that an important opportunity to understand the patient's concept of the disease was lost. ${ }^{42}$ Greater cognizance of patients' existing understanding and awareness may reduce unnecessary information sharing, freeing up more time for patientcentered discussion. We observed that practitioners tended to regard diabetes as a pathophysiologic problem affecting organ systems, whereas patients focused on the associated social difficulties. ${ }^{17}$

In undertaking care for patients with newly diagnosed diabetes, a more useful starting point might be to assume or at least consider that patients have some prior knowledge of and experience with diabetes management and complications through family or friends. Far from finding a linear sequence whereby a "novice" patient became an "expert," 23 we observed a patchy evolution of expertise that often built on an unacknowledged platform of patient expertise.

\section{Time and Teamwork}

Lack of time is a major preoccupation of health professionals in primary care. In this cohort, a considerable amount of time was allocated to some patients' care over the 6-month period, as shown in Figure 1, but this time was not always used optimally. Although time required may vary according to the initial complexity of the diabetes presentation, with some patients having considerable physical, psychological, and social issues, much of the observed variation was due to unplanned reduplication of educational efforts, and a lack of coordination between different health professionals.

Coordination of care improves outcomes, ${ }^{43}$ but sequential consultations in this study were often characterized by fragmented contributions of different health professionals. The lack of coordination in their relative contribution to patient care meant that high levels of motivational interviewing expertise were often undermined by duplication of information and advice.

These findings suggest that time spent in consultations should be reviewed for appropriateness, and health professionals should agree on who will cover various aspects of education so that repetition is avoided unless intended.

\section{Evolution of Self-Management}

Although there has been some discussion about the importance of developing diabetes self-management expertise, ${ }^{28}$ this study is the only example we could find describing directly observed development of such expertise in a general practice setting. Our cited examples illustrate the transition of patients from novice to expert in terms of diabetes knowledge and self-management over the 6-month follow-up. Progress along this evolutionary pathway depended on both patient and health professional factors. Quotes provided for PT01, and those of some other patients, show general practice as an environment in which the spectrum of current health behavior change theories are displayed with a focus on self-management and empowerment, and skillful use by health professionals of motivational interviewing and acknowledgment of the stages of change. ${ }^{44,45}$ In other cases, as exemplified by PT03, the patient and professional were still stuck at the end of the 6 -month period, with the patient continuing to be treated as a novice. These findings align with some of the themes identified in other studies and commentary highlighting the importance of social and contextual factors in the development of self-management expertise. ${ }^{28,46}$

\section{Conclusion}

In this study, we identified a number of structural and procedural barriers to optimal diabetes care that could be addressed by enhanced communication with patients and improved communication between members of the primary care team. Strengths of current systems include some coordination of services, high levels of communication skills, and flexibility in time and health professional role allocations. Challenges to 


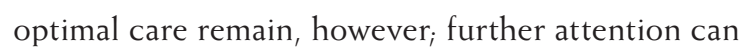
be given to identifying preexisting patient knowledge; reducing the role of biomedical language and allowing a broader scope for the role of the social context

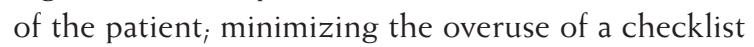
approach; and developing more effective strategies for health professional information sharing to reduce unplanned duplication for the patient. Video tracking methods potentially provide a strategy for effecting some of these changes, by using the data generated for reflective practice with the primary care teams. ${ }^{47}$

\section{To read or post commentaries in response to this article, see it online at http://www.AnnFamMed.org/content/16/1/37.}

Key words: diabetes; primary care; disease management; patient education; health communication; practice-based research

Submitted March 3, 2013; submitted, revised, May 24, 2017; accepted June 23, 2017.

Author contributions: T.D., M.S., K.D., L.M., T.K., and N.S. designed the study. L.M., N.S., B.D., D-A.H., L.G., D.R., and R.T. undertook fieldwork and data collection/processing. L.M., S.V., and R.T. viewed and reviewed recorded data and made written summaries of each item and collated cases. All authors contributed to the data analysis. T.D. and M.S. drafted the manuscript, and all authors read and approved the final manuscript.

Funding support: The study was funded by the Health Research Council of New Zealand.

Previous presentations: Aspects of these findings have been presented at the European Association of Communication in Health conference; September 2010; Verona, Italy; the New Zealand Medical Association annual GP conference; June 2011; Rotorua, New Zealand; ; the Conversation Analysis of Clinical Encounters conference; July 12-14, 2011; York, United Kingdom; and the Annual Scientific and General Meeting of the New Zealand Society for the Study of Diabetes; May 2012; Queenstown, New Zealand.

Acknowledgments: The study was funded by the Health Research Council of New Zealand. The researchers thank the many patients and health professionals who participated.

\section{References}

1. Jacob S, Serrano-Gil M. Engaging and empowering patients to manage their type 2 diabetes, Part II: Initiatives for success. Adv Ther. 2010;27(10):665-680.

2. King H, Aubert RE, Herman WH. Global burden of diabetes, 1995 2025: prevalence, numerical estimates, and projections. Diabetes Care. 1998;21(9):1414-1431.

3. Moore MP, Lunt H. Diabetes in New Zealand. Diabetes Res Clin Pract. 2000;50(Suppl 2):S65-S71.

4. Blakely T, Dew K. Ethnicity, acculturation and health: who's to judge? N Z Med J. 2004;117(1188):U742.

5. Street RL Jr, Makoul G, Arora NK, Epstein RM. How does communication heal? Pathways linking clinician-patient communication to health outcomes. Patient Educ Couns. 2009;74(3):295-301.

6. Sheridan NF, Kenealy TW, Kidd JD, et al. Patients' engagement in primary care: powerlessness and compounding jeopardy. A qualitative study. Health Expect. 2015;18(1):32-43.
7. Griffin S. Diabetes care in general practice: meta-analysis of randomised control trials. BMJ. 1998;317(7155):390-396.

8. Simmons D, Kenealy T. Optimising ambulatory diabetes care in the information age: primary care, secondary care or integrated care? N Z Med J. 1999;112(1080):1-3.

9. Hobden A. Strategies to promote concordance within consultations. Br J Community Nurs. 2006;11(7):286-289.

10. Collins S, Drew P, Watt I, Entwistle V. 'Unilateral' and 'bilateral' practitioner approaches in decision-making about treatment. Soc Sci Med. 2005;61(12):2611-2627.

11. Williams S, Weinman J, Dale J. Doctor-patient communication and patient satisfaction: a review. Fam Pract. 1998;15(5):480-492.

12. Stewart MA. Effective physician-patient communication and health outcomes: a review. CMAJ. 1995;152(9):1423-1433.

13. Makoul G, Clayman ML. An integrative model of shared decision making in medical encounters. Patient Educ Couns. 2006;60(3): 301-312.

14. Barry CA, Bradley CP, Britten N, Stevenson FA, Barber N. Patients' unvoiced agendas in general practice consultations: qualitative study. BMJ. 2000;320(7244):1246-1250.

15. Cegala DJ, McClure L, Marinelli TM, Post DM. The effects of communication skills training on patients' participation during medical interviews. Patient Educ Couns. 2000;41(2):209-222.

16. Burke JA, Earley M, Dixon LD, Wilke A, Puczynski S. Patients with diabetes speak: exploring the implications of patients' perspectives for their diabetes appointments. Health Commun. 2006;19(2):103-114.

17. Cohen MZ, Tripp-Reimer T, Smith C, Sorofman B, Lively S. Explanatory models of diabetes: patient practitioner variation. Soc Sci Med. 1994;38(1):59-66.

18. Ciechanowski $P$, Katon WJ. The interpersonal experience of health care through the eyes of patients with diabetes. Soc Sci Med. 2006; 63(12):3067-3079.

19. Collins S. Explanations in consultations: the combined effectiveness of doctors' and nurses' communication with patients. Med Educ. 2005;39(8):785-796.

20. Parry O, Peel E, Douglas M, Lawton J. Issues of cause and control in patient accounts of type 2 diabetes. Health Educ Res. 2006;21(1): 97-107.

21. Rhodes P, Langdon M, Rowley E, Wright J, Small N. What does the use of a computerized checklist mean for patient-centered care? The example of a routine diabetes review. Qual Health Res. 2006;16(3): 353-376.

22. Fhärm E, Rolandsson $\mathrm{O}$, Johansson EE. 'Aiming for the stars'-GPs' dilemmas in the prevention of cardiovascular disease in type 2 diabetes patients: focus group interviews. Fam Pract. 2009;26(2):109-114.

23. van Dulmen AM, Verhaak PF, Bilo HJ. Shifts in doctor-patient communication during a series of outpatient consultations in noninsulin-dependent diabetes mellitus. Patient Educ Couns. 1997;30(3): 227-237.

24. Hampson SE, McKay HG, Glasgow RE. Patient-physician interactions in diabetes management: consistencies and variation in the structure and content of two consultations. Patient Educ Couns. 1996; 29(1):49-58.

25. Asan O, Montague E. Using video-based observation research methods in primary care health encounters to evaluate complex interactions. Inform Prim Care. 2014;21(4):161-170.

26. Dowell A, Macdonald L, Stubbe M, Plumridge E, Dew K. Clinicians at work: What can we learn from interactions in the consultation? N Z Fam Physician. 2007;34(5):345-350.

27. van Dillen SM, Noordman J, van Dulmen S, Hiddink GJ. Examining the content of weight, nutrition and physical activity advices provided by Dutch practice nurses in primary care: analysis of videotaped consultations. Eur J Clin Nutr. 2014;68(1):50-56. 
28. Paterson B, Thorne S. Developmental evolution of expertise in diabetes self-management. Clin Nurs Res. 2000;9(4):402-419.

29. Karhila P, Kettunen T, Poskiparta M, Liimatainen L. Negotiation in type 2 diabetes counseling: from problem recognition to mutual acceptance during lifestyle counseling. Qual Health Res. 2003;13(9): 1205-1224.

30. Matthews SM, Peden AR, Rowles GD. Patient-provider communication: understanding diabetes management among adult females. Patient Educ Couns. 2009;76(1):31-37.

31. Parry O, Peel E, Douglas M, Lawton J. Patients in waiting: a qualitative study of type 2 diabetes patients' perceptions of diagnosis. Fam Pract. 2004;21(2):131-136.

32. McHale CT, Laidlaw AH, Cecil JE. Direct observation of weightrelated communication in primary care: a systematic review. Fam Pract. 2016;33(4):327-345.

33. Loewe R, Schwartzman J, Freeman J, Quinn L, Zuckerman S. Doctor talk and diabetes: towards an analysis of the clinical construction of chronic illness. Soc Sci Med. 1998;47(9):1267-1276.

34. Sarangi S. Towards a communicative mentality in medical and healthcare practice. Commun Med. 2004;1(1):1-11.

35. Nessa J, Malterud K. Discourse analysis in general practice: a socio linguistic approach. Fam Pract. 1990;7(2):77-83.

36. Abdulhadi N, Al-Shafaee MA, Ostenson CG, Vernby A, Wahlström R Quality of interaction between primary health-care providers and patients with type 2 diabetes in Muscat, Oman: an observational study. BMC Fam Pract. 2006;7:72

37. Creswell JW. Research Design: Qualitative, Quantitative, and Mixed Methods Approaches. Thousand Oaks, CA: Sage Publications; 2013.
38. Altheide $\mathrm{DL}$, Johnson JM. Reflections on interpretive adequacy in qualitative research. In: Denzin NK, Lincoln YS, eds. The SAGE Handbook of Qualitative Research. 4th ed. Thousand Oaks, CA: Sage; 2011:581-594.

39. Macdonald L, Stubbe M, Tester R, et al. Nurse-patient communication in primary care diabetes management: an exploratory study. BMC Nurs. 2013;12(1):20.

40. Simmons D, Gamble GD, Foote S, Cole DR, Coster G; New Zealand Diabetes Passport Study. The New Zealand Diabetes Passport Study: a randomized controlled trial of the impact of a diabetes passport on risk factors for diabetes-related complications. Diabet Med. 2004;21(3):214-217.

41. Kettunen T, Poskiparta M, Kiuru P, Kasila K. Lifestyle counseling in type 2 diabetes prevention: a case study of a nurse's communication activity to produce change talk. Commun Med. 2006;3(1):3-14.

42. Freeman J, Loewe R. Barriers to communication about diabetes mellitus. Patients' and physicians' different view of the disease. $J$ Fam Pract. 2000;49(6):507-512.

43. Sturmberg JP, Overend D. General practice based diabetes clinics. An integration model. Aust Fam Physician. 1999;28(3):240-245.

44. Prochaska JO, Velicer WF. The transtheoretical model of health behavior change. Am J Health Promot. 1997;12(1):38-48.

45. Bandura A. Health promotion by social cognitive means. Health Educ Behav. 2004;31(2):143-164.

46. Funnell MM, Anderson RM. Empowerment and self-management of diabetes. Clin Diabetes. 2004;22(3):123-127.

47. Holmström I, Larsson J, Lindberg E, Rosenqvist U. Improving the diabetes-patient encounter by reflective tutoring for staff. Patient Educ Couns. 2004;53(3):325-332.

\section{Get the Annals of Family Medicine by E-mail}

Make sure you see every new issue

while it's fresh; have the table of

contents sent to you by e-mail for

easy access to articles of interest.

Don't miss important research.

Request the e-mail table of contents at

http://www2.highroadsolution.com/

aafp_annals_preference_center/search.aspx

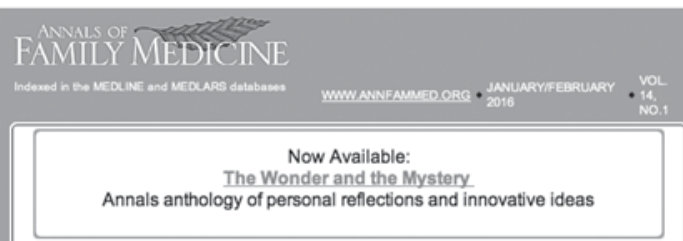

The All text of the journal is avallable online at hthp / thumw annfammed, org and through various MEDLINE and MEDLARS, Sdience Citation Index Expanded, Current Contents Clinical Medicine, PSyclNFO, EMBASE, and CINHAL databases:

EDirÓRIALS

In This Issues Size Matters

Achieving PCMH Status May Not Be Meaningtul for Small Practices

The Paradox of Size: How Small, Independent Practices Can Thrive in Valve-Based Carte Farad Mostashar

ORIGINAL RESEARCH

Solo and Small Practices: A Vital, Diverse Part of Primary Cary

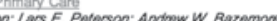
Family physicians in solo and small practices outnumber those in larger practices.

Large Indegandent Primary Care Medical Groups

have the potential to make primary care attractive to physicians

Primary Care Physician Panel Size and Quality of Care: A Pooviation-Based Study in Ontario.

Simone Dahrouge; Wwilam Hogg: Jaime Younger, Elizabeth Muggah; Grant Russell; Richard H 